\title{
Wpływ mechanizacji spawania złączy rurowych metodą FCAW (136) na właściwości procesu
}

\author{
Influence of mechanization on the properties \\ of the pipelines 136 welding process
}

\section{Streszczenie}

W artykule porównano warunki oraz efekty ręcznego i automatycznego spawania złączy doczołowych na rurociągach przesyłowych z użyciem metody 136, to jest spawania w osłonie gazu aktywnego drutem proszkowym z rdzeniem topnikowym. Artykuł jest efektem wieloletniej współpracy firmy JT Sp. z o.o. z Warszawy, która zajmuję się budownictwem gazociągów oraz instalacji gazowych z Zakładem Inżynierii Spajania Politechniki Warszawskiej. W artykule zaprezentowano i przedyskutowano rezultaty wykonywania wypełnienia oraz lica spoin czołowych rur na przykładzie grupy liniowej spawaczy pracującej przy realizacji gazociągu wysokiego ciśnienia. Porównania dokonano w kontekście warunków i parametrów spawania oraz czasu wykonywania spoin.

Słowa kluczowe: FCAW, spawanie ręczne i automatyczne, wydajność spawania

\section{Abstract}

The article compares the conditions and the obtained effects of manual and automatic welding of butt joints on transmission pipelines using the method 136 in gasshielded with flux cored wire (Flux Cored Arc Welding). The article is a effect of many years of collaboration between JT Sp. Z o. o. from Warsaw (which builds gas pipelines and other gas installations) with the Department of Welding Engineering of Warsaw University of Technology. The article presented and discussed the results of the experience of filling of throat of weld and welding of face of weld on the example of the linear group working on the implementation of high-pressure pipeline. The comparison was made in the context of terms and welding parameters and manufacture time of the welds.

Keywords: FCAW, manual and automatic welding, efficiency of welding

\section{Inwestycje w systemie przesyłowym gazu}

Pod koniec 2013 roku GAZ SYSTEM, czyli jeden z największych inwestorów na rynku polskich rurociągów, przedstawił „Plan rozwoju - w zakresie zaspokojenia obecnego zapotrzebowania na paliwa gazowe na lata 2014-2023", w którym umieszczono plany inwestycyjne w Polsce na kolejne lata. GAZ SYSTEM jest odpowiedzialny za transport paliw gazowych siecią przesyłową na terenie całego kraju, w celu ich dostarczenia do sieci dystrybucyjnych oraz do odbiorców końcowych podłączonych do systemu przesyłowego. W poniższej tabeli przedstawiony jest wykaz najważniejszych inwestycji, których przewidywany termin realizacji to rok 2018 .

Wykonanie tak szeroko zakrojonych inwestycji w tak krótkim czasie, jest wyzwaniem dla polskich podmiotów gospodarczych budujących gazociągi. Opisana sytuacja stwarza sposobność do znaczącego wzmocnienia pozycji rynkowej firmy JT Sp. z o.o. Jednym z najważniejszych wymogów przy przystąpieniu do przetargów na inwestycje z tablicy I jest mechanizacja i automatyzacja procesu spawalniczego.

\section{Zmechanizowane spawanie złączy ruro- wych metodą FCAW (136)}

Mechanizując zaawansowane procesy spawalnicze w wytwarzaniu rurociągów, można warunkowo osiągnąć niską wadliwości złączy na poziomie 5\%, jak i wysoką wydajność, która nie jest osiągalna podczas stosowania spawania ręcznego. W większości przypadków wytwarzanie rurociągów w Polsce bazuje nadal na ręcznym spawaniu metodami $111,141,135$ oraz $136[1 \div 6]$. Zmiana spawania ręcznego na zmechanizowane niesie za sobą duże inwestycje związane z zakupem urządzeń spawalniczych [7] oraz przygotowaniem personelu do wymogów mechanizacji procesu spawalniczego. Pozornie w automatyzacji dominujące jest znaczenie urządzeń, jednak bardzo istotną kwestią jest zmiana mentalności i sposobu pracy operatorów/spawaczy jak i osób nadzorujących.

Spawanie w osłonie gazu aktywnego drutem proszkowym z rdzeniem topnikowym ze względu na stosunkowo wysoką wydajność stapiania jest coraz częściej stosowane do wytwarzania złączy w konstrukcjach wielkogabarytowych oraz często kojarzone jest z mechanizacją.

Inż. Konrad Wojnarowski - JT Sp. z o.o. Warszawa; dr hab. inż. Tomasz Chmielewski, prof. PW; dr hab. inż. Dariusz Golański, prof. PW - Politechnika Warszawska, dr inż. Marek Węglowski - Akademia Spawania. 
Tablica I. Zestawienie najważniejszych inwestycji w gazowym systemie przesyłowym w Polsce w perspektywie 2018 roku

Table I. The Summary of the most important gas investments in the transmission system in Poland up to the 2018 year

\begin{tabular}{|c|c|c|}
\hline Inwestycje w perspektywie 2018r. & $\begin{array}{c}\text { Średnica } \\
\text { rury } \\
{[\mathrm{mm}]}\end{array}$ & $\begin{array}{c}\text { Długość } \\
\text { rurociągu } \\
{[\mathrm{km}]}\end{array}$ \\
\hline Polkowice-Żary & 300 & 63,7 \\
\hline Lasów-Jeleniów & 700 & 17,5 \\
\hline Gałów-Kiełczów & 500 & 41,7 \\
\hline Czeszów-Wierzchowice & 1000 & 14 \\
\hline Czeszów-Kiełczów & 1000 & 33 \\
\hline Zdzieszowice-Wrocław & 1000 & 130 \\
\hline Zdzieszowice-Kędzierzyn & 1000 & 19 \\
\hline Polska-Czechy & 1000 & 60 \\
\hline Tworóg-Kędzierzyn & 1000 & 47 \\
\hline Tworzeń-Tworóg & 1000 & 56 \\
\hline Lwówek-Odolanów & 1000 & 179 \\
\hline Hermanowice-Strachociny & 700 & 72 \\
\hline Mory-Piotrków Trybunalski & 400 & 6 \\
\hline Rembelszczyzna-Mory & 700 & 28 \\
\hline Wronów-Kozienice & 500 & 30 \\
\hline
\end{tabular}

W odróżnieniu od metody 135 materiał dodatkowy ze względu na rdzeń w formie proszku topi się szybciej, a dodatkowo tworzy żużel ochraniający jeziorko ciekłego metalu, wprowadzając dodatki stopowe do jeziorka oraz zmniejszając szkodliwy wpływ atmosfery powietrza. Po ostygnięciu na powierzchni jeziorka tworzy się żużel, który chroni krystalizujący metal spoiny przed wpływem otoczenia i szybkim stygnięciem. Po wystygnięciu spoiny należy usunąć żużel.

Korzyści wynikające z mechanizacji procesów wytwarzania [8,9]:

- dążenie do humanizacji procesu,

- stałe podnoszenie jakości pracy,

- poprawa efektywności procesów spawalniczych,

- wzrost wydajności na stanowiskach spawalniczych,

- wyższy współczynnik wykorzystania urządzeń produkcyjnych,

- wyższa jakość produkcji,

- rytmiczność produkcji,

- możliwość optymalizacji parametrów spawania,

- możliwość zatrudnienia pracowników po krótkim kursie szkolenia zawodowego,

- zmniejszenie liczby wybraków,

- możliwość ograniczenia kosztownych i czasochłonnych procesów kontroli jakości,

- możliwość zwiększenia czasu jarzenia łuku nawet do 80\% (podczas spawania ręcznego w warunkach podanych porównaniu w niniejszym artykule osiągane jest zaledwie $20 \%$ ).

$\mathrm{Na}$ rysunku 1 zaprezentowano mechanizację procesu 136 podczas spawania połączeń rurowych, których warunki spawania analizowano w niniejszym artykule. Na rysunku 2 pokazano grupę liniową, tzw. czołówkę, zorganizowaną grupę spawalniczą wykonującą spoiny czołowe w połączeniach rurowych. Grupa liniowa wykonuje sekcje składające się z kilku do kilkuset metrowych odcinków rur. Długość sekcji jest zależna od łuków oraz kolizji występujących na trasie gazociągu. W trakcie budowy gazociągów ok. $80 \%$ spoin wykonywanych jest przez grupę liniową. Pozostałe $20 \%$ wykonywane są przez grupy montażowe, które łączą sekcje wykonane przez grupę liniową poprzez wykonywanie spoin w wykopie. Typowa czołówka spawalnicza składa się z dźwigu bocznego, który ma za zadanie dokładać kolejne rury i pomaga przy ustawianiu rur podczas montażu z zastosowaniem centrownika wewnętrznego lub zewnętrznego który umożliwia precyzyjne wzajemne ustalanie elementów złącza. Ostatnim elementem systemu jest widoczna na rysunku 2. spawalnica wraz z HDS oraz namiotem spawalniczym. Na spawalnicy umieszczany jest agregat prądotwórczy wraz ze źródłami spawalniczymi oraz gazy do podgrzewania płomieniowego i gazy ochronne. HDS umieszczony na spawalnicy służy do ustawiania namiotu spawalniczego w miejscu wykonywania złącza spawanego. W namiocie spawalniczym wykonywane jest złącze spawane, znajduje się w nim oświetlenie oraz systemy wentylacyjne. Namiot spawalniczy służy przede wszystkim do ochronny przed negatywnym oddziaływaniem warunków atmosferycznych.

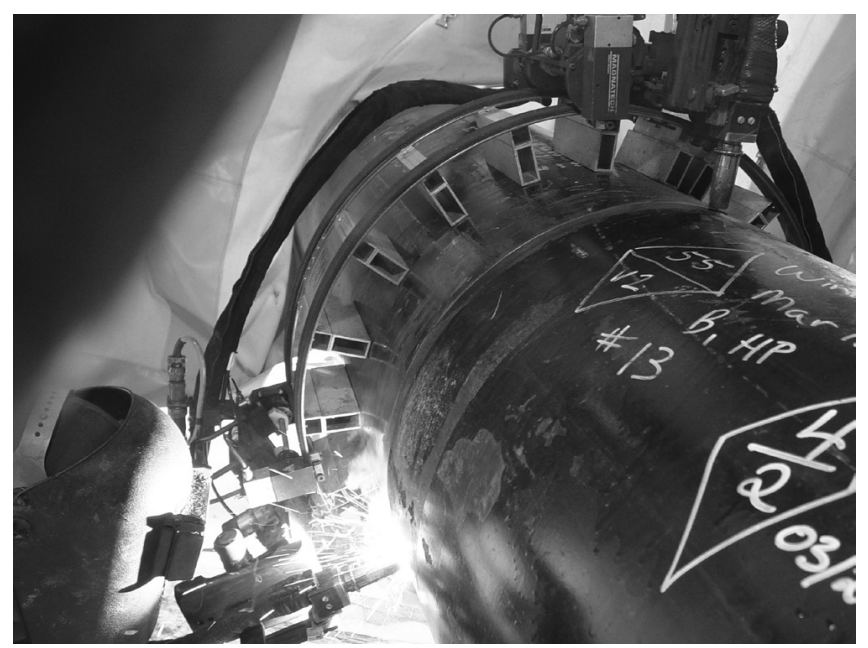

Rys. 1. Mechanizacja spawania rurociągu metodą FCAW (136) Fig. 1. Mechanization of pipeline welding with FCAW method (136)

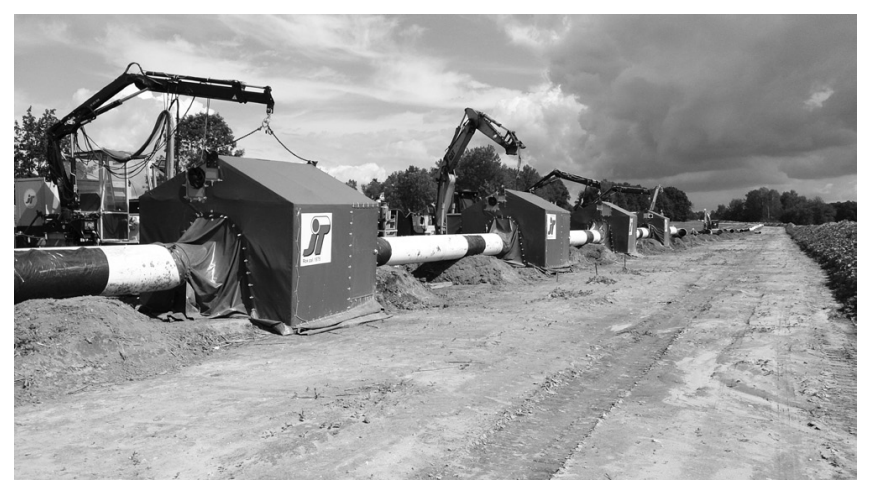

Rys. 2. Zdjęcie grupy liniowej

Fig. 2. Picture of linear group

\section{Warunki technologiczne spawania}

W porównywaniu warunków i rezultatów spawania ręcznego i zmechanizowanego, uwzględniono w analizie tylko wypełnienie i lico przedmiotowych spoin czołowych, aby wyniki porównania uznać za miarodajne w obu przypadkach zagwarantowano takie same warunki w kwestii geometrii przygotowania brzegów rur do spawania (ukosowania). Do spawania przetopów w obu wariantach zaangażowano innowacyjną odmianę metody MAG SpeedRoot, opisywaną wcześniej przez autorów w literaturze [2], SpeedRoot jest to innowacyjna niskoenergetyczna odmiana metody spawania MAG dedykowana do spawania ściegu 
graniowego spoin czołowych wykonywanych w pozycji PJ (z góry do dołu), wprowadzona przez firmę Rywal-RHC na polski rynek na początku roku 2011. Główną zaletą jaka wyróżnia SpeedRoot spośród konkurencji, jest jej program sterujący oraz specjalnie zaprojektowana funkcja synergiczna. Należy również wspomnieć, że firma JT Sp. z o.o. była jedyną w Polsce, a może i na świecie, którą wykonała tą metodą ścieg graniowy na połączeniach rurowych, uzyskała również uznanie tej technologii w Urzędzie Dozoru Technicznego. Poniżej przedstawiono rysunku 3 geometrii krawędzi rur przygotowanych do spawania ściegu graniowego.

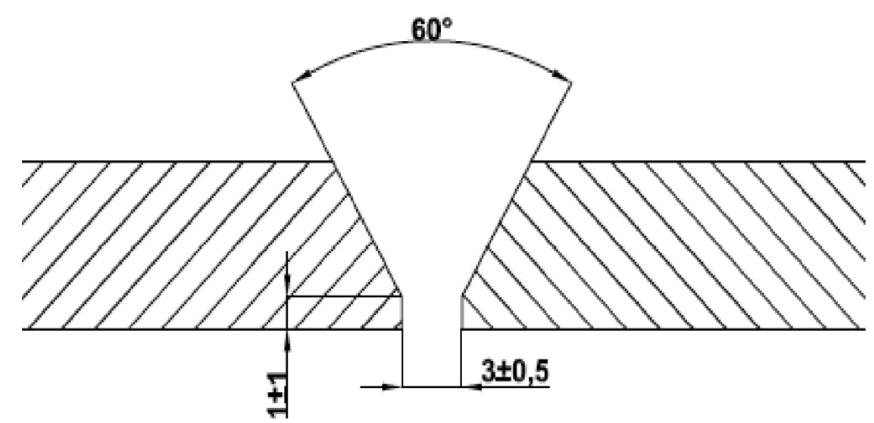

Rys. 3. Rysunek przygotowanie brzegów

Fig. 3. Drawing of edge preparation

\section{Zastosowane w porównaniu techniki spawania metodą 136}

Zastosowano technikę spawania ręcznego metodą 136 realizowaną "z dołu do góry" łukiem krótkim, ściegami zakosowymi, gwarantując prawidłowe wypełnienie rowka oraz łatwe wypływanie żużla na powierzchnię. Po ostygnięciu należy usunąć powstały żużel. Spawanie ręczne najczęściej można spotkać w firmach wykonujących produkcje jednostkową, małoseryjną oraz przy pracach montażowych i remontowych. Wcześniej wspomniano o umiejętnościach spawacza oraz ich wpływie na jakości połączeń spawanych, nie bez znaczenie pozostaje źródło energii. Na rynku urządzeń spawalniczych, występuje duża liczba urządzeń umożliwiających wykonywanie złącza spawanego metodą 136.

Spawanie zmechanizowane oznacza zastępowanie pracy ręcznej spawacza przy wykonywaniu złącza spawanego. Do najczęściej mechanizowanych metoda spawalniczych należą metody 135, 136, 131 oraz 121. Mimo że prace wykonuje maszyna to cała odpowiedzialności za jakości wykonanego złączą nadal spoczywa na człowieku, który ustawia parametry spawania oraz kontroluje proces za pośrednictwem panelu sterowniczego. W warunkach opisanego porównania technika spawania zmechanizowanego była taka sama, jak technika spawania ręcznego.

\section{Zastosowane materiały}

Podczas porównywania wszystkie złącza wykonywane były na rurze ze stali L485MB. L485MB (wg EN 10208-2) bądź $X 70$ (wg API 5L), jest to stal na rury przewodowe po obróbce termomechanicznej. Właściwości materiału podstawowego przedstawiono w tablicach II i III.

Podczas porównywania wszystkie złącza wykonane zostały drutem elektrodowym proszkowym Pipeweld 91T-1 (właściwości w tabl. IV i V) z rdzeniem topnikowym rutylowym. Można go stosować do stali o minimalnej granicy plastyczności do $540 \mathrm{MPa}$.

Tablica II. Skład chemiczny stali L485MB

Table II. Chemical composition of L485MB steel

\begin{tabular}{|c|c|c|c|c|c|c|c|c|c|c|}
\hline \multirow{2}{*}{$\begin{array}{c}\text { Oznacze- } \\
\text { nie } \\
\text { stali }\end{array}$} & \multicolumn{9}{|c|}{ Zawartość pierwiastków [\%] } & \multirow{2}{*}{ Max. } \\
\cline { 2 - 10 } & $\mathrm{C}$ & $\mathrm{Si}$ & $\mathrm{Mn}$ & $\mathrm{P}$ & $\mathrm{S}$ & $\mathrm{V}$ & $\mathrm{Nb}$ & $\mathrm{Ti}$ & inne & CEV \\
\hline L485MB & 0,16 & 0,45 & 1,7 & 0,025 & 0,020 & 0,10 & 0,06 & 0,06 & $\begin{array}{c}\mathrm{V}+\mathrm{Nb}+\mathrm{Ti} \\
<0,15 \%\end{array}$ & 0,43 \\
\hline
\end{tabular}

Tablica III. Właściwości mechaniczne stali L485MB

Table III. Mechanical properties of L484MB

\begin{tabular}{|c|c|c|c|}
\hline Symbol stali & Granica plastyczności $\mathrm{R}_{\mathrm{t} 0,5}\left[\mathrm{~N} / \mathrm{mm}^{2}\right]$ & Wytrzymałość $\mathrm{R}_{\mathrm{m}}\left[\mathrm{N} / \mathrm{mm}^{2}\right]$ & Wydłużenie $\mathrm{A}_{\text {min, }}[\%]$ \\
\hline L485MB & $485-605$ & 507 & 18 \\
\hline
\end{tabular}

Tablica IV. Skład chemiczny drutu elektrodowego Pipeweld 91T-1

Table IV. Chemical composition of filler metal Pipeweld 91 T-1

\begin{tabular}{|c|c|c|c|c|c|c|c|c|c|c|c|c|c|}
\hline \multirow[b]{2}{*}{ Nazwa } & \multirow{2}{*}{$\begin{array}{l}\text { Produ- } \\
\text { cent }\end{array}$} & \multicolumn{12}{|c|}{ Zawartość pierwiastków } \\
\hline & & C & $\mathrm{Si}$ & $\mathrm{Mn}$ & Mo & $\mathrm{Ni}$ & $\mathrm{Cr}$ & $\mathrm{Cu}$ & $\mathrm{P}$ & $S$ & V & Al & $\begin{array}{c}\mathrm{Ti} \\
+\mathrm{Zr}\end{array}$ \\
\hline $\begin{array}{c}\text { Pipeweld } \\
91 \mathrm{~T}-1\end{array}$ & Esab & 0,04 & 0,36 & 1,17 & 0,17 & 0,88 & 0,03 & - & 0,01 & 0,01 & 0,02 & - & - \\
\hline
\end{tabular}

Tablica V. Właściwości mechaniczne drutu Pipeweld 91T-1

Table V. Mechanical properties of filler metala Pipeweld 91T-1

\begin{tabular}{|c|c|c|c|c|}
\hline Nazwa & $\begin{array}{c}\text { Granica plastyczno- } \\
\text { ści [MPa] }\end{array}$ & $\begin{array}{c}\text { Wytrzymałość na rozciąga- } \\
\text { nie [MPa] }\end{array}$ & $\begin{array}{c}\text { Wydłużenie } \\
{[\%]}\end{array}$ & $\begin{array}{c}\text { Próba wytrzymałości } \\
\text { w temperaturze }-40{ }^{\circ} \mathrm{C}\end{array}$ \\
\hline $\begin{array}{c}\text { Pipeweld } \\
\text { 91T-1 }\end{array}$ & 604 & 670 & 25 & $95 \mathrm{~J}$ \\
\hline
\end{tabular}


Warunki porównania

spawania ręcznego

\section{z zmechanizowanym}

Porównano warunki i rezultaty spawania dwóch grup spawalniczych, przy czym jedna wykonuje złącza spawane ręcznie druga zaś w sposób zmechanizowany. Obie grupy wykonały 1000 spoin na rurze $\emptyset 711 \times 11,0 \mathrm{~mm}$ ze stali L485MB, z wcześniej przygotowanym przetopem. Specyfika wykonywania złączy spawanych na połączeniach rurowych wymaga spawania $w$ duecie, czyli jednocześnie wykonywany jest ten sam ścieg z obu stron rury. Podczas spawania korzystano z gazu M21 przy natężeniu przepływu $15 \div 20 \mathrm{l} / \mathrm{min}$. temperatura podgrzewania wstępnego $100{ }^{\circ} \mathrm{C}$, temperatura międzyściegowa $150{ }^{\circ} \mathrm{C}$. Obie grupy wykonywały dwie warstwy wypełnienia oraz jedną warstwę lica. Na rysunku 4 przedstawiono schemat ułożenie poszczególnych ściegów.

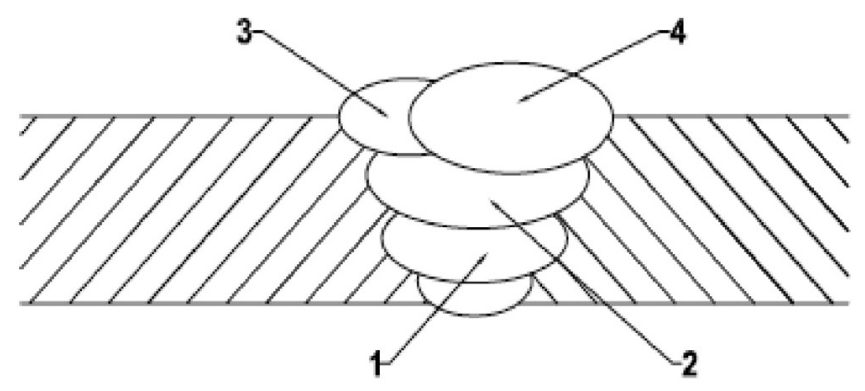

Rys. 4. Schemat kolejności wykonywania poszczególnych ściegów Fig. 4. Scheme of the order of execution of the various beads

W przypadku organizacji pracy na czołówce spawalniczej kierowano się zasadą - grupy robocze wszystkich namiotów muszą być równomiernie obciążone. W namiocie pierwszym wykonuje się ścieg 1, w drugim ścieg 2, zaś w trzecim wykonuje się ścieg 3 i 4 . Przy tym podziale pracy zostało zagwarantowane równomierne obciążenie pracą. Podczas wykonywania złączy spawanych monitorowane były parametry spawania (tabl. VI), jak i czas spawania oraz czas czynności pomocniczych.

W trakcie wykonywania złączy spawanych mierzony był czas spawania jak i czas czynności pomocniczych związanych z pracą grupy „ręcznej” i „zmechanizowanej”. Zaproponowany system pracy na czołówce spawalniczej, która bierze udział w porównaniu jest najskuteczniejszym sposobem podczas wykonywania złączy spawanych w budowie rurociągów czy gazociągów. W tym systemie każdy grupa w poszczególnym namiocie ma do wykonania swoją część cyklu pracy. Przez to uzyskiwana jest ciągłość pracy całej grupy spawalniczej. Aby w pełni przedstawić różnicę miedzy spawaniem ręcznym i zmechanizowanym, przeanalizowano i porównano warunki realizacji 1000 spoin na rurze DN700x11,0 mm ze stali L485MB. Przyjęty został 10 godzinny dzień pracy, w którym operacje spawalnicze trwają faktycznie 9 godzin.
Tablica VI. Zestawienie parametrów spawania Table VI. Comparison of welding parameters

\begin{tabular}{|c|c|c|c|c|c|}
\hline \multirow{2}{*}{ Parametr } & \multirow{2}{*}{ Numer } & \multicolumn{2}{|c|}{ Grupa ręczna } & \multicolumn{2}{|c|}{$\begin{array}{c}\text { Grupa } \\
\text { zmechanizowana }\end{array}$} \\
\hline & & $\max$ & $\min$ & $\max$ & $\min$ \\
\hline \multirow{4}{*}{$\begin{array}{l}\text { Natężenie } \\
\text { prądu } \\
\text { spawania, } \\
\text { [A] }\end{array}$} & 1 & 180 & 160 & 219 & 182 \\
\hline & 2 & 210 & 190 & 222 & 195 \\
\hline & 3 & 205 & 190 & 205 & 178 \\
\hline & 4 & 205 & 190 & 210 & 182 \\
\hline \multirow{4}{*}{$\begin{array}{c}\text { Napięcie łuku, } \\
\text { [V] }\end{array}$} & 1 & 23,5 & 22 & 24 & 22,4 \\
\hline & 2 & 25 & 23 & 25 & 22,5 \\
\hline & 3 & 24,6 & 22,8 & 24,8 & 22,4 \\
\hline & 4 & 24,6 & 22,8 & 24,8 & 22,4 \\
\hline \multirow{4}{*}{$\begin{array}{c}\text { Prędkość } \\
\text { spawania } \\
{[\mathrm{mm} / \mathrm{s}]}\end{array}$} & 1 & 2,2 & 2 & 4,7 & 2,99 \\
\hline & 2 & 2,25 & 2,2 & 2,85 & 2,5 \\
\hline & 3 & 2,4 & 2,3 & 3,08 & 2,6 \\
\hline & 4 & 2,4 & 2,3 & 3,25 & 3,1 \\
\hline \multirow{4}{*}{$\begin{array}{l}\text { Energia } \\
\text { liniowa } \\
\text { spawania } \\
{[\mathrm{kJ} / \mathrm{mm}]}\end{array}$} & 1 & 1,73 & 1,3 & 0,88 & 1,46 \\
\hline & 2 & 1,9 & 1,5 & 1,88 & 1,39 \\
\hline & 3 & 1,8 & 1,7 & 1,88 & 1,28 \\
\hline & 4 & 1,8 & 1,7 & 1,46 & 1,13 \\
\hline \multirow{4}{*}{$\begin{array}{c}\text { Amplituda } \\
\text { oscylacji } \\
\text { [mm] }\end{array}$} & 1 & 8 & 6 & 8 & 6 \\
\hline & 2 & 10 & 6 & 10 & 6 \\
\hline & 3 & 6 & 4 & 6 & 4 \\
\hline & 4 & 8 & 5 & 8 & 5 \\
\hline \multirow{4}{*}{$\begin{array}{c}\text { Częstotliwość } \\
\text { oscylacji } \\
{[1 / \mathrm{s}]}\end{array}$} & 1 & 1,25 & 0,8 & 1,25 & 0,8 \\
\hline & 2 & 1,25 & 0,75 & 1,25 & 0,8 \\
\hline & 3 & 1,1 & 0,75 & 1,1 & 0,75 \\
\hline & 4 & 1,1 & 0,5 & 1,1 & 0,75 \\
\hline $\begin{array}{c}\text { Czas } \\
\text { zatrzymania } \\
\text { w pozycji } \\
\text { zwrotnej } \\
\text { oscylacji [s] }\end{array}$ & $1-4$ & 0,6 & 0,5 & 0,6 & 0,5 \\
\hline
\end{tabular}

Tablica VII. Porównanie rezultatów spawania ręcznego i zmechanizowanego Table VII. Comparison of the results of manual and mechanized welding process

\begin{tabular}{|c|c|c|c|}
\hline $\begin{array}{c}\text { Rodzaj grupy } \\
\text { spawalniczej }\end{array}$ & $\begin{array}{c}\text { Czas potrzebny } \\
\text { do wykonania } \\
1 \text { złącza }\end{array}$ & $\begin{array}{c}\text { Czas pracy jednego } \\
\text { dnia [s] }\end{array}$ & $\begin{array}{c}\text { Dzienna liczba spin dni potrzebna } \\
\text { do wykonania } \\
1000 \text { spoin }\end{array}$ \\
\hline zmechanizowana & 1487 & 32400 & 21,78 \\
\hline ręczna & 2078 & 32400 & 15,59 \\
\hline
\end{tabular}




\section{Podsumowanie}

Rok 2015 dla branży gazowniczej będzie przełomowy. Jest to rok rozpoczęcia największych inwestycji na polskim rynku, które niosą za sobą wysokie wymagania odnośnie jakości, jak i technologii wykonywania złączy spawanych. Mowa jest o wymaganej mechanizacji procesu podczas wykonywania połączeń spawanych. W polskich firmach zajmujących się realizacją inwestycji gazowych, proces zmiany sposobu wykonywania złączy spawanych trwa już od kilku lat. W celu spełnienia wymagań stawianych przez głównego inwestora na polskim rynku GAZ SYSTEM. Autorzy obrali za cel niniejszej pracy porównanie właściwości i efektów spawania ręcznego i zmechanizowanego. Porównania dokonano na przykładzie grupy spawalniczej wykonującej złącza spawane na rurze DN700x11,0 mm ze stali L485MB. Porównano dwie grupy wykonujące złącza spawane, tą samą metodą spawania, jednak różnymi sposobami. W powyższej pracy porównano metodę ręczną ze zmechanizowaną na podstawie: parametrów spawania oraz czasu pracy. Na koniec zobrazowano pracochłonność wykonania 1000 spoin przez obie te grupy. Zestawienie parametrów spawania ujawniło o wiele wyższą prędkość spawania zmechanizowanego, przy porównywalnych wartości parametrów spawania oraz utrzymaniu odpowiedniego poziomu ilości ciepłą wprowadzanego do złącza. Na przykładzie 1000 spoin pokazano jaki wpływ ma mechanizacja procesu spawania na czas realizacji zadania. Mechanizacja na przykładzie czołówki spawalniczej nie zmienia systemu pracy całej grupy, zmiana dotyczy tylko spawania i czynności związanych ze spawaniem, reszta pozostaje taka jak przy spawaniu ręcznym. Jednak czy to w przypadku spawania ręcznego czy zmechanizowanego to człowiek nadal jest najważniejszym ogniwem i to on ma największy wpływ na jakość, efektywność oraz wydajności procesu wykonywania złączy spawanych.

\section{Literatura}

[1] T. Chmielewski, M. Węglowski, K. Kudła "Spawanie w pozycji PF metodą MMA z wykorzystaniem nowej funkcji UP w zasilaczach inwertorowych zbudowanych w technice MICOR" Przegląd Spawalnictwa, Vol. 86, Nr. 9, s. 45-49, 2014.

[2] M. Węglowski, T. Chmielewski, K. Kudła "Ocena wydajności spawania niskoenergetycznego procesu SpeedRoot w pozycji PG "Przegląd Spawalnictwa, Vol. 83, Nr. 12, s. 26-30, 2011.

[3] B. Pawłowski, J. Krawczyk, P. Bała, S. Parzych, M. Paćko „Jakość złączy spawanych rurociągu wody chłodzącej wykonanego ze stali austenitycznej X6CrNiTi18-10" Przegląd Spawalnictwa, Vol. 82, Nr. 4, s. 4-7, 2010.

[4] R. Krawczyk, J. Plewniak, K. Sujewicz "Spawanie metodą MAG grubościennych rurociągów energetycznych ze stali 13HMF - optymalizacja warunków procesu" Przegląd Spawalnictwa, Vol. 78, Nr. 7-10, 2006.
[5] K. Y. Lee, K. Sadurski „Budowa rurociągów przesyłowych oraz możliwości zastosowanianowych kryteriów oceny jakości spoin obwodowych" Przegląd Spawalnictwa, Vol. 81, Nr. 6, s. 6-9, 2009.

[6] T. Chmielewski „Projektowanie procesów technologicznych - Spawalnictwo" Oficyna Wydawnicza Politechniki Warszawskiej, Warszawa, 2013.

[7] T Chmielewski, M Węglowski „Analiza rynku spawalniczego w Polsce pod względem sprzedaży urządzeń oraz materiałów spawalniczych" Przegląd Spawalnictwa vol. 82, nr 6, s. 28-31, 2010.

[7] T. Sałaciński „SPC statystyczne sterowanie procesami produkcji”, Oficyna Wydawnicza Politechniki Warszawskiej, Warszawa, 2009.

[8] T. Sałaciński, W. Sosnowski "System nadzorowania jakości procesów spawalniczych zgodny z wymaganiami ISO 3834 w oparciu o standardy ISO 9001-część 1", Przegląd Spawalnictwa, Vol. 87, nr 4, s. 10-13, 2015. 